\title{
BMJ Open Female genital cosmetic surgery: a cross- sectional survey exploring knowledge, attitude and practice of general practitioners
}

\author{
M Simonis, ${ }^{1,2}$ R Manocha, ${ }^{3,4}$ J J Ong $^{5,6}$
}

To cite: Simonis M, Manocha R, Ong JJ. Female genital cosmetic surgery: a cross-sectional survey exploring knowledge, attitude and practice of general practitioners. BMJ Open 2016;6:e013010. doi:10.1136/bmjopen-2016013010

- Prepublication history and additional material is available. To view please visit the journal (http://dx.doi.org/ 10.1136/bmjopen-2016013010).

Received 15 June 2016 Revised 11 August 2016 Accepted 1 September 2016

CrossMark

For numbered affiliations see end of article.

\section{Correspondence to}

Dr M Simonis;

magdalena.simonis@mac. com

\section{ABSTRACT}

Objective: To explore general practitioner's (GP) knowledge, attitudes and practice regarding female genital cosmetic surgery (FGCS) in Australia.

Design: Cross-sectional survey.

Setting: Australia.

Sample: GPs who attended a women's health seminar and GPs who subscribed to a non-governmental, national health professional organisation database that provides education to primary care professionals.

Method: A national online survey of GPs was conducted for the 10-week period, starting 1 week prior and 2 months after a Women's Health seminar was held in Perth on 8 August 2015. 31 questions prompted GPs' knowledge, attitudes and practice in managing patients asking about FGCS.

Results: The survey was fully completed by 443 GPs; $54 \%$ had seen patients requesting FGCS. Overall, $75 \%(95 \% \mathrm{Cl} 71 \%$ to $79 \%$ ) of GPs rated their knowledge of FGCS as inadequate and $97 \%(95 \% \mathrm{Cl}$ $94 \%$ to $99 \%$ ) had been asked by women of all ages about genital normality. Of those who had seen patients requesting FGCS, nearly half $(44 \%, 95 \% \mathrm{Cl}$ $38 \%$ to $51 \%$ ) reported they had insufficient knowledge of risks of FGCS procedures and $35 \%$ (95\% Cl $29 \%$ to $41 \%$ ) reported seeing females younger than 18 years of age requesting FGCS. Just over half $(56 \%, 95 \% \mathrm{Cl} 51 \%$ to $60 \%)$ of the GPs felt that women should be counselled before making a referral for FGCS. More than half the GPs suspected psychological disturbances in their patients requesting FGCS such as depression, anxiety, relationship difficulties and body dysmorphic disorder.

Conclusions: GPs see women of all ages presenting with genital anatomy concerns and in those who request FGCS, GPs often suspected a range of mental health difficulties. GPs require greater education to support their patients who request FGCS.

\section{INTRODUCTION}

The popularity of female genital cosmetic surgery (FGCS) is growing and genital modification for cosmetic reasons has many social

\section{Strengths and limitations of this study}

- This is the first large survey that explores general practitioner (GP) experience of female genital cosmetic surgery (FGCS).

- Nearly, all GPs surveyed have been asked about genital normality in women of all ages.

- Thirty-five percent of GPs had been asked about FGCS by girls under the age of 18 .

- The survey confirms the need for further education of GPs.

- This is a skewed group of GPS with mainly women's health interest.

and medical implications. FGCS, also known as vulvoplasty, refers to a group of nonmedically indicated cosmetic surgical procedures that change the structure and appearance of the healthy external genitalia of women, or internally in the case of vaginal tightening. ${ }^{2}$ More specifically, it encompasses labiaplasty (trimming of the labia minora and less commonly labia majora), hymenoplasty, vaginoplasty (also known as vaginal reconstruction), mons pubis liposuction, vaginal 'rejuvenation' or laser 'rejuvenation', G-spot augmentation and Orgasm-shot. ${ }^{1}{ }^{2}$ Following liposuction, breast augmentation and rhinoplasty, labiaplasty was reported to be the fourth most common cosmetic surgical procedure according to US statistics in 2013, rising by $44 \%$ in the 2013 alone. ${ }^{3}$ Over the decade 2003-2013, Australia had a threefold increase in labiaplasties ${ }^{4}$ and the UK a fivefold increase. ${ }^{5}$ Australian government statistics indicate a $140 \%$ increase in requests for rebatable vulvoplasty from 640 in 2001 to more than 1500 in $2013,{ }^{4}$ without a concomitant rise in genital disease diagnoses. ${ }^{6}$ These figures do not reflect the true number of procedures performed, as an unknown number of procedures are performed in the private sector for which there are no accurate published figures. 
Much of the research published to date has emanated from the UK and USA. It has explored sociocultural reasons for the rise in FGCS procedures, ${ }^{78}$ the ethical aspects regarding its heavy marketing by sectors of the medical profession ${ }^{7-11}$ and surgical discourse regarding techniques, ${ }^{12}{ }^{12-15}$ with little published literature for the medical profession discussing risks and long-term outcomes of FGCS. ${ }^{15} 16$ The role of the general practitioner (GP) regarding this emerging area of surgery has been identified as a 'new dilemma for the general practitioner (GP), 91017

A recently published qualitative study from Australia interviewed 27 health professionals of which 13 were GPs. ${ }^{18}$ This study revealed that although all of the GP participants were aware of FGCS and all practitioners had seen patients who had questioned whether their genital appearance was normal, they were unaware of how to best manage these consultations. In response to the increasing demand for FGCS and advice sought from the GPs regarding FGCS, the Royal Australian College of General Practitioners launched the resource guide for health professionals titled, 'Female Genital Cosmetic Surgery: a resource for general practitioners and other health professionals' on 31 July $2015 .{ }^{19}$ As the first point of contact with the healthcare system, informed GPs can play an important and central role in educating women and girls regarding the varied range of genital appearance and the risks of genital surgery. ${ }^{17}$ They can also help to address modifiable psychosocial factors, thereby assisting women towards better health outcomes. $^{717}$

To date, limited quantitative research has explored the management of FGCS from the GP perspective. This study addresses a significant research gap by being the first to explore the knowledge, attitude and practice regarding FGCS in a large group of GPs.

\section{METHODS}

\section{Study population}

In order to recruit GPs, the online survey (see online supplementary file 1) and Information Statement (see online supplementary file 2) were sent via email three times at intervals of 3 days each, to 11000 GPs. This group of GPs voluntarily subscribes to a private educational organisation database to receive free seminar information, material, invitations and updates in matters pertaining to primary healthcare and this database has been in existence since the year 2000. The RACGP guidelines were published and launched on 31 July 2015. The survey was first sent out on 3 August 2015 and during the Women's and Children's seminar, at which an FGCS information session for GPs was held on 8 August 2015. It was considered important to send out the survey prior to the seminar and as close to the launch of the RACGP guidelines, in order to assess a baseline of GP knowledge. The survey ran for the 10-week period and was closed when the response rate remained at 1 , for 3 consecutive weeks which also coincided with a GP response rate of around $1 \%$ of the national GP population and $4 \%$ of the database GP population. The Raosoft sample size calculator was used (http://www. raosoft.com/samplesize.html) to attain a confidence level of $95 \%$ and margin error of $5 \%$. Accordingly, the largest sample size required from the estimated 33275 GPs in Australia was 380. The number of survey responses preceding the seminar reached 379 and following the seminar, there were 64 . Of the 64 respondents, it is not possible to differentiate between those who attended the FGCS information session and those who did not.

\section{Data collection}

Survey Monkey was used to create and administer the online survey (see online supplementary file 1), which was prepared by two GPs (MS, RM) and a Sexual Health physician (JJO). The survey items contained questions about the GP's knowledge, attitudes and practice regarding FGCS. Two open-ended items on the GP's attitudes to FGCS were included at the end of the survey, inviting free text responses. The survey was pilot tested with 20 primary care health professionals before distribution. This was a voluntary opt in, anonymous survey and no incentives were offered to participants. Only the fully completed surveys were examined.

\section{Analysis}

Participant demographics and their knowledge, attitudes and practice variables were analysed descriptively. Ninety-five percent CIs were calculated for proportions using the modified Wald method. All analyses were performed using the statistical software, STATA (Statacorp. 2013. Stata Statistical Software: Release 13). The 2 open-ended questions were manually analysed by 3 researchers independently and the 6 main themes and 29 subthemes were agreed on. We used a qualitative descriptive research approach, a pragmatic approach commonly used in health science research as it aims to provide straight descriptions of events or topics in everyday language rather than an interpretive or theory-based analysis. $^{20} 21$

This research was approved by the Alfred Health Human Ethics Committee (Project 348/15).

\section{RESULTS}

There were 443 fully completed GP survey responses out of a total of 461. Each incomplete response was manually examined and the decision to exclude the information was based on the failure to progress beyond the first question. Tables 1-3 give the overview of the 443 respondents' knowledge, practice and attitudes; tables 4-7 look closer at the 242 GPs who have seen women requesting FGCS.

Demographics are summarised in table 1 where comparison is made to nationwide data. The majority (74\%) 
Table 1 Demographics of general practitioners

\begin{tabular}{|c|c|c|}
\hline Demographics & $\begin{array}{l}\text { Study participants }(\mathrm{n}=443) \\
\mathrm{n}(\%, 95 \% \mathrm{CI})\end{array}$ & $\begin{array}{l}\text { Australian General Practice } \\
\text { National Workforce Statistics* } \\
2014-2015(\mathrm{n}=33275) \\
\mathrm{n}(\%, 95 \% \mathrm{Cl})\end{array}$ \\
\hline Mean age $(\mathrm{SD})$ in years & $52.9(11.2)$ & $\begin{array}{l}\text { Unavailable as mean age; NWS data } \\
\text { show age distribution as total: } \\
<35 \text { years: } 4413 \\
\text { age 35-44: } 5262 \\
\text { age 45-54: } 8609 \\
\text { age 55-64: } 7773 \\
\text { age65-74: } 3605 \\
\text { age } 75+: 773\end{array}$ \\
\hline Duration of practice (SD), years & $23.7(12.4)$ & Unavailable \\
\hline Female & $327(74 \%, 70 \%$ to $78 \%)$ & 14695 (44\%, 44\% to $45 \%)$ \\
\hline \multicolumn{3}{|l|}{ Location of practice } \\
\hline Urban & $218(49 \%, 45 \%$ to $54 \%)$ & 22427 (67\%, 67\% to $68 \%)$ \\
\hline Outer metropolitan & $109(25 \%, 21 \%$ to $29 \%)$ & $6326(19 \%, 19 \%$ to $19 \%)$ \\
\hline Rural+remote & $112(25 \%, 21 \%$ to $30 \%)$ & $3836(12 \%, 11 \%$ to $12 \%)$ \\
\hline Missing & $4(1 \%, 0 \%$ to $2 \%)$ & $686(2 \%, 2 \%$ to $2 \%)$ \\
\hline \multicolumn{3}{|l|}{ GP special interest in } \\
\hline Women's health & $340(77 \%, 73 \%$ to $80 \%)$ & \multirow{5}{*}{$\begin{array}{l}\text { National data indicating GP practice interest } \\
\text { areas were unavailable }\end{array}$} \\
\hline Mental health & $181(41 \%, 36 \%$ to $46 \%)$ & \\
\hline Sexual health & $155(35 \%, 31 \%$ to $40 \%)$ & \\
\hline Obstetrics/gynaecology & $122(28 \%, 24 \%$ to $32 \%)$ & \\
\hline Cosmetic surgery & $26(6 \%, 4 \%$ to $8 \%)$ & \\
\hline
\end{tabular}

Table 2 Knowledge general practitioners have regarding female genital cosmetic surgery $(n=443)$

\begin{tabular}{|c|c|}
\hline $\begin{array}{l}\text { Knowledge GPs have } \\
\text { regarding FGCS }(n=443)\end{array}$ & n (\%, 95\% Cl) \\
\hline $\begin{array}{l}\text { GP feels they did not have } \\
\text { adequate knowledge of FGCS }\end{array}$ & $333(75 \%, 71 \%$ to $79 \%)$ \\
\hline \multicolumn{2}{|c|}{ GP feels confident assessing genital appearance } \\
\hline In female patients & $337(76 \%, 72 \%$ to $80 \%)$ \\
\hline & $287(65 \%, 60 \%$ to $69 \%)$ \\
\hline \multicolumn{2}{|c|}{ GP acquired information regarding FGCS from } \\
\hline Media & $74(17 \%, 14 \%$ to $20 \%)$ \\
\hline Conf & 96 \\
\hline & $11 \%, 8 \%$ to $14 \%)$ \\
\hline RAC & $26(6 \%, 4 \%$ to $8 \%)$ \\
\hline & $26 \%)$ \\
\hline Consumer websites & $30(7 \%, 5 \%$ to $10 \%)$ \\
\hline \multicolumn{2}{|c|}{$\begin{array}{l}\text { GP feels confident to give patient adequate advice for } \\
\text { each of the following procedures }\end{array}$} \\
\hline Labiaplasty & $130(54 \%, 47 \%$ to $60 \%)$ \\
\hline asty & $83(34 \%, 29 \%$ to $40 \%)$ \\
\hline & $62(26 \%, 21 \%$ to $31 \%)$ \\
\hline & $59(24 \%, 19 \%$ to $30 \%)$ \\
\hline Clitoral hood reduction & $55(23 \%, 18 \%$ to $28 \%)$ \\
\hline Vulval liposuction & $34(14 \%, 10 \%$ to $19 \%)$ \\
\hline & $10(4 \%, 2 \%$ to $7 \%)$ \\
\hline G-spot augmentation & $11(5 \%, 3 \%$ to $8 \%)$ \\
\hline
\end{tabular}

of GP participants were women (95\% CI 70 to 78 ) and the mean age of all participants was 52.9 years with a mean duration of practice being 23.7 years. The majority of respondents $(77 \%, 95 \%$ CI $73 \%$ to $80 \%)$ expressed a special interest in women's health.

Analysis of GP knowledge of FGCS procedures (table 2) showed that $75 \%$ (95\% CI $71 \%$ to $79 \%)$ of total GPs rated their knowledge about FGCS as inadequate and they accessed information from conferences $(22 \%, 95 \%$ CI $18 \%$ to $26 \%)$, other health professionals $(22 \%, 95 \%$ CI $18 \%$ to $26 \%)$ and the media $(17 \%, 95 \%$ CI $14 \%$ to $20 \%)$. When participants were asked if they felt confident to give advice for each of the FGCS procedures, the responses ranged from $4 \%$ to $54 \%$.

About half of the GPs $(56 \%, 95 \%$ CI $51 \%$ to $60 \%)$ felt that a woman should be counselled before proceeding to FGCS (table 3) and that FGCS should not be performed on women $<18$ years, unless for genuine medical reasons $(53 \%, 95 \%$ CI $48 \%$ to $57 \%)$. A third $(33 \%, 95 \%$ CI $29 \%$ to $38 \%$ ) indicated they needed more information before developing an opinion about FGCS requests and some indicated that if a woman requested FGCS, it was a matter of freedom of choice regardless of whether or not the GP felt it was appropriate or in the patient's best interests $(21 \%, 95 \%$ CI $17 \%$ to $25 \%)$. Few GPs 
Table 3 General practitioner attitudes to female genital cosmetic surgery $(n=443)$

GP attitudes to FGCS ( $n=443)$

n (\%, 95\% Cl)

I need more information before developing my opinion

$147(33 \%, 29 \%$ to $38 \%)$

If a woman wants this (FGCS), it is her choice

$92(21 \%, 17 \%$ to $25 \%)$

FGCS should not be performed on women $<18$ years unless for genuine medical reasons

$233(53 \%, 48 \%$ to $57 \%)$

A woman should be counselled first before referral for FGCS

$247(56 \%, 51 \%$ to $60 \%)$

FGCS is acceptable even when only for cosmetic reasons

$44(10 \%, 7 \%$ to $13 \%)$

FGCS is unacceptable when only for cosmetic reasons

$64(14 \%, 11 \%$ to $18 \%)$

FGCS is not different from other types of cosmetic surgery, in my opinion

$95(21 \%, 18 \%$ to $26 \%)$

Table 4 GP experience and management of patients who are considering FGCS $(n=242)$

\begin{tabular}{lr}
\hline GP experience and management of patients who are considering FGCS (n=242) & $\mathbf{n ~ ( \% , ~ 9 5 \% ~ C l ) ~}$ \\
\hline GPs who have seen patient aged $<18$ requesting FGCS & $84(35 \%, 29 \%$ to $41 \%)$ \\
Patient asked GP about opinion of genital normality & $235(97 \%, 94 \%$ to $99 \%)$ \\
Patient asked GP for genital examination & $177(73 \%, 67 \%$ to $78 \%)$ \\
GP examined genitalia & $181(75 \% 69 \%$ to $80 \%)$ \\
All the time & $34(14 \%, 10 \%$ to $19 \%)$ \\
Sometimes & $157(65 \%, 59 \%$ to $71 \%)$ \\
Patient asked GP opinion regarding FGCS & $143(59 \%, 53 \%$ to $65 \%)$ \\
GP felt comfortable discussing aspects of FGCS on request from patient & $157(65 \%, 59 \%$ to $71 \%)$ \\
Patient requested referral for FGCS from GP & \\
GP discussed risks of FGCS procedures with patient & $99(41 \%, 35 \%$ to $47 \%)$ \\
All the time & $25(10 \%, 7 \%$ to $15 \%)$ \\
Sometimes & $11(5 \%, 3 \%$ to $8 \%)$ \\
Only if they ask me & $107(44 \%, 38$ to 51$)$ \\
I am not sufficiently aware of risks to discuss & $83(43 \%, 29 \%$ to $40 \%)$ \\
GP felt confident discussing short-term risks of FGCS & $57(24 \%, 19 \%$ to $29 \%$ \\
GP felt confident discussing long-term risks of FGCS & \\
Resources GPs used as information sources for patient consultations & $85(35 \%, 29 \%$ to $41 \%)$ \\
Labia Library (website, www.labialibrary.com) & $85(35 \%, 29 \%$ to $41 \%)$ \\
Diagrams & $53(22 \%, 17 \%$ to $28 \%)$ \\
Anatomy books & $21(9 \%, 6 \%$ to $13 \%)$ \\
Consumer websites & $21(9 \%, 6 \%$ to $13 \%)$ \\
RACGP FCGS resource &
\end{tabular}

considered FGCS acceptable when only for cosmetic reasons $(10 \%, 95 \%$ CI $7 \%$ to $13 \%)$.

Table 4 summarises the responses of 242 GPs who have managed patients specifically requesting FGCS and indicates how they rate their knowledge and what they have experienced. Overall, the number of requests for referrals from these GPs per annum were low in number with the most common range given being 1-10 per year. The majority of these GPs $(88 \%, 95 \%$ CI $83 \%$ to $92 \%)$ had been asked for a referral for surgery but only a minority felt confident advising patients about shortterm risks $(34 \%, 95 \%$ CI $29 \%$ to $40 \%$ ) and long-term risks $(24 \%, 95 \%$ CI $19 \%$ to $29 \%)$ associated with FGCS procedures and less than half of the GPs $(41 \%, 95 \%$ CI $35 \%$ to $47 \%$ ) discussed risk with their patients all of the time. The majority of these GPs $(73 \%, 95 \%$ CI $67 \%$ to $78 \%$ ) were asked by patients for a genital examination in conjunction with the request for referral and $75 \%$ of GPs (95\% CI 69 to 80) always examined the genital area of women requesting FGCS.
Virtually, all the GPs who responded to the survey ( $97 \%, 95 \%$ CI $94 \%$ to $99 \%$ ) had been asked by patients regarding genital normality at some time, independently of a request for FGCS information or referral. Not all of the GPs, however, expressed confidence in assessing female genital anatomy $(76 \%, 95 \%$ CI $72 \%$ to $80 \%)$. The age range of patients seen by GPs requesting FGCS referral varied from as young as 10 years to as old as 65 and about a third $(35 \%, 95 \%$ CI $29 \%$ to $41 \%$ ) of GPs had been asked about FGCS by girls under the age of 18 .

Table 5 provides a list of modifiable psychosocial problems that were identified by the majority of respondents as significantly affecting a woman's motivation to have FGCS and an overall $41 \%$ (95\% CI $36 \%$ to $46 \%$ ) of the GPs listed mental health as an area of practice interest also. More than half of all the GPs surveyed suspected the following conditions as 'often' or 'sometimes' contributing to their patients' request to have FGCS: anxiety $(67 \%, 95 \%$ CI $60 \%$ to $72 \%)$, 
Table 5 General practitioner diagnoses or suspects the following psychosocial issues in women who request FGCS ( $n=242)$

\begin{tabular}{ll}
\hline & $\begin{array}{l}\text { General practitioners } \\
\text { suspected these factors as } \\
\text { 'sometime/most of the time' }\end{array}$ \\
Psychosocial factors & $\mathbf{n}(\%, 95 \% \mathbf{C l})$ \\
\hline Anxiety & $161(67 \%, 60 \%$ to $72 \%)$ \\
Relationship difficulties & $143(59 \%, 53 \%$ to $65 \%)$ \\
Body dysmorphic disorder & $133(55 \%, 49 \%$ to $61 \%)$ \\
Depression & $121(50 \%, 44 \%$ to $56 \%)$ \\
Sexual dysfunction & $101(42 \%, 36 \%$ to $48 \%)$ \\
Eating disorders & $68(28 \%, 23 \%$ to $34 \%)$ \\
History of sexual abuse & $57(24 \%, 19 \%$ to $29 \%)$ \\
Domestic violence & $30(12 \%, 9 \%$ to $17 \%)$ \\
\hline
\end{tabular}

relationship difficulties (59\%, 95\% CI 53\%) and body dysmorphic disorder (55\%, $95 \%$ CI $49 \%$ to $61 \%)$. Table 6 outlines the list of the social factors influencing the perceived need for FGCS listed in the survey; $100 \%$ $(95 \%$ CI $98 \%$ to $100 \%)$ of the GPs thought their patients were most commonly influenced by each of fashion (appearance in clothes), comfort in clothes, perception of beauty and pornography. An adjoining column in table 6 correlates some free text responses given by the GPs, to these same factors.

The key themes revealed in the open-ended questions are listed in table 7. A typical comment from one GP suggests that GPs see many women with genital anatomy concerns and few for FGCS requests stated: "I do not have many women asking me questions about FGCS, they sometimes ask for referral to surgeons they have heard of. But almost on a daily basis I have women ask me if their genitals look 'normal' and often wish their labia were smaller" (female, aged 28 years, urban practice, 3 years, women's health interest, trained in Australia). The GPs who responded were mostly female with an interest in women's health, which implies that self-selection may have occurred. A possible explanation for this is suggested in this open-ended statement, "While our practice specializes in women's health, I suspect most patients considering FGCS discuss this with the female GPs-I am a mere male and have only rarely had a discussion re this matter with a female patient" (male aged 70, urban practice for 30 years, women's health interest, trained overseas).

The significance of the genital examination was encapsulated by one respondent: "This is what happens in my rooms. I see people who worry that they may not look normal. They always look normal. I reassure them of such. They usually appear very relieved. I try to address reasons for their concern, and with this I guess I close the door by and large on some potential requests for surgery" (female, aged 50, urban practice, 22 years, women's health interest, trained in Australia).

Interestingly, the following statement suggests that genital concerns are not always expressed by the patient and they might therefore not be addressed: "At first pap smear or when examining a young woman for the first time I will always comment 'everything looks entirely normal' the response is always 'relief' even when I wasn't aware there was any anxiety beforehand" (female, aged 52, rural practice, 25 years, women's health interest, trained in Australia).

A free text response from a female GP aged 34 years (urban practice, 8 years, trained in Australia) explains why genital examination is not always undertaken: "Most of my patients have been so set on having it done that they were not open to counselling, an examination of the genitals etc."

Others reported a lack of knowledge and need for further GP education, "I think we should know more to be able to counsel our patients. Currently I just refer them as I cannot answer their questions" (female, aged 28, urban practice, 3 years, women's health interest, trained in Australia).

\section{DISCUSSION}

This study is the largest study to examine GP knowledge, attitudes and practice in a previously little explored area. The majority of GPs who responded were female, primarily interested in women's health and had more than two decades of GP experience. We elicited themes that GPs should play a central role in being the primary source of information regarding FGCS, provide genital anatomy advice, assess for concurrent mental health issues and appropriately refer as necessary (table 7).

The findings suggest that nearly all GPs have seen women with genital normality concerns and of the patients who request FGCS, GPs often suspected or diagnosed a range of psychological problems. GPs were seen to be important in screening for mental health issues and providing relief for genital anxiety concerns (table 7). More than a third of the GPs have seen girls under 18 requesting FGCS and the majority of the GPs felt in need of more information to support their patients.

The findings regarding genital anatomy concerns among women are consistent with a large international survey, which explored women's knowledge and attitudes to their genital appearance ${ }^{22}$ and found that only $27 \%$ stated that they knew their vaginal appearance exactly, $48 \%$ had a reasonable idea and $24 \%$ had a partial idea, or no idea at all. Similarly, a small qualitative study of 21 university students conducted in Australia indicated that young women had little knowledge of genital appearance, anatomy and diversity. ${ }^{23}$ Although $97 \%$ of the GPs in this study had been asked about genital normality, examination was performed in only $77 \%$ of consultations, which correlates with published research from the $\mathrm{UK}^{8}$ which found that only $77 \%$ of referrers reported physically examining the patient.

There are many complex issues that can unfold following an apparently simple remark such as 'am I normal down there?'. GPs can reassure women, but only if they 
Quantitative component: what social

influences impact patients who ask about

FGCS?

Fashion (comfort in clothes)

$\mathrm{n}=\mathbf{2 4 2}(\%, \mathbf{9 5 \%} \mathrm{Cl})$

Qualitative component: examples of 'free text' responses which reveal subthemes also listed in table 7

$242(100 \%, 98 \%$ to $100 \%)$

"some women do have extremely large labia minora that protrude and are visible in swimwear, are uncomfortable" (female, aged 47, 20 years in outer metropolitan practice women's health interest, trained in Australia)

Perception of beauty

$242(100 \%, 98 \%$ to $100 \%) \quad$ "Reflects a social shift to the importance of appearance over values and substance and perhaps another way we devalue and objectify women" (male, aged 55, 20 years rural practice, Obstetric interest, trained in Australia)

Pornography

$242(100 \%, 98 \%$ to $100 \%)$

"Most patients I see requesting genital cosmetic surgery are extremely poorly informed about normal anatomy, based on porn" (female, aged 45, 8 years urban practice, sexual health interest, trained in Australia)

Perception of normal

$206(85 \%, 80 \%$ to $89 \%)$

"The trend for 'full Brazilian' hair removal has 'uncovered' vulvas and made them more 'visible' to women and their partners. Many people think that a 'normal' vulva is supposed to look somewhat pre-pubertal" (female, aged 60, 35 years urban practice, women's health, trained in Australia)

Spouse/partner comments

$132(55 \%, 48 \%$ to $61 \%)$

Physical discomfort

$102(42 \%, 36 \%$ to $48 \%)$

Consumer websites

$69(29 \%, 23 \%$ to $25 \%)$

Fashion (appearance in clothes)

$54(22 \%, 18 \%$ to $28 \%)$

Peer comments

$41(17 \%, 13 \%$ to $22 \%)$
"It is a dangerous fashion-relates a lot to partner pressure and young males watching easily available internet pornography in my opinion" (female, aged 64, 35 years in outer metropolitan practice, women's health, trained in UK)

"Had been coerced to have FGCS by her ex-husband who humiliated her and made her feel she was abnormal and unlovable" (female, aged 56, 30 years urban practice, women's health, trained in UK)

"Excessive labia minora may be very uncomfortable with excessive discharge and irritation" (female aged 57, 25 years in urban practice, women's health, trained in Australia)

"The majority of requests have been due to media presenting skewed version of normality, influencing both partners. Only one patient request due to physical discomfort" (female, aged 57, 20 years in urban practice, women's health interest, trained in Australia)

"In the vast majority of patients I think they have been swayed by the media/ online information re what is normal. I really don't think females used to be overly concerned until recently" (male, aged 57, 21 years in urban practice, obstetric interest, trained in Australia)

"I think the overwhelming access to internet visual images is a major factor in women's perception of 'normal' even if they do not disclose this to us" (female, aged 54, 30 years in urban practice, women's health, trained in Australia)

"Fashions change-even sexual and genital cosmetic fashions. Loss of genital tissue to comply with fashion,..." (male, aged 51, 23 years in outer metropolitan urban practice, women's health interest, trained in Australia)

"Peer group pressure, in younger age groups, seems to be one of the most important factors promoting the decision to seek FGCS" (male, aged 60, 31 years in urban practice,

\section{factors promoting the decision to seek
women's health interest, trained in UK)}


Table 7 Major themes from free text responses to Question 30: "What is your opinion regarding the role of GPS for FGCS?" Total responses 417 ( $n$ 443)

\begin{tabular}{|c|c|}
\hline Major theme & Subtheme \\
\hline $\begin{array}{l}\text { GP is seen as an educator: (i)regarding } \\
\text { FGCS } \\
\text { (ii)genital anatomy }\end{array}$ & $\begin{array}{l}\text { Source of information regarding FGCS } \\
\text { - Information regarding risks of FGCS } \\
\text { Provides access to information regarding FGCS } \\
\text { - Provider of 'normal anatomy advice' } \\
\text { - Reassures women regarding their normality }\end{array}$ \\
\hline $\begin{array}{l}\text { GP is seen as the 'gateway' to referral } \\
\text { pathway }\end{array}$ & $\begin{array}{l}\text { GP should be able to assess women regarding need for surgery. } \\
\text { GP should avoid providing referral when only for 'cosmetic' or 'aesthetic' } \\
\text { reasons. } \\
\text { GP should refer to gynaecologist rather than to plastic surgeon } \\
\text { GP seen as 'first port of call' by patients } \\
\text { - GP should refer to psychologist psychiatrist for mental health issues }\end{array}$ \\
\hline $\begin{array}{l}\text { GPs request information regarding } \\
\text { FGCS }\end{array}$ & $\begin{array}{l}\text { Need more information regarding risks of FGCS } \\
\text { Need more information regarding FGCS practices } \\
\text { Patients expect GP to know about FGCS and genital anatomy } \\
\text { GP issued referral in past due to lack of information about FGCS } \\
\text { Lack of information is a cause of low confidence giving advice } \\
\text { - Need more information in order to form opinion regarding FGCS }\end{array}$ \\
\hline $\begin{array}{l}\text { GP examination of genital area is } \\
\text { necessary }\end{array}$ & $\begin{array}{l}\text { Provider of reassurance } \\
\text { - Routine gynaecological examination is an opportunity to educate women } \\
\text { regarding genital normality } \\
\text { - Examination on expression of genital anatomy concern }\end{array}$ \\
\hline $\begin{array}{l}\text { GP screen for mental health issues is } \\
\text { important }\end{array}$ & $\begin{array}{l}\text { GP role is to provide or refer for counselling } \\
\text { GP reassurance provides relief of minor anxiety symptoms } \\
\text { - Reme serious mental health issues may present with genital anxiety concerns } \\
\text { - Relations issues can cause genital anxiety concerns }\end{array}$ \\
\hline GP role is very important & $\begin{array}{l}\text { For patient education } \\
\text { For patient reassurance regarding normality } \\
\text { For appropriate referral } \\
\text { - GP is seen as a reliable source of information }\end{array}$ \\
\hline GP performs multiple functions & $\begin{array}{l}\text { GP should 'listen, examine reassure, counsel, then if necessary refer' } \\
\text { This is a sociocultural trend, outside the realm of medicine }\end{array}$ \\
\hline
\end{tabular}

themselves are confident of normality. As depictions of genital anatomy are sparse in the medical literature, ${ }^{24}$ it is not surprising that only $75 \%$ of GPs were confident in evaluating normality of female genital anatomy.

More than half of the participant responses suggested that women seeking advice for FGCS may be in an emotionally vulnerable state, as GPs suspected or diagnosed a range of psychological difficulties. There is evidence that GPs deal with multiple issues per consultation and are identifying mental health issues such as depression more frequently than 10 years ago. ${ }^{25}$ These findings correlate with a study that explored online forums for reasons women were enquiring about labiaplasty and compared them with the reasons they gave the surgeons for wanting the modification. ${ }^{26}$ The study suggested that contrary to reasons patients gave their surgeon such as their ability to exercise due to rubbing or chafing of genital tissue, the online forums disclosed deeper emotional distress due to anxiety regarding normality, aesthetics, embarrassment or even sexual anxiety related to this. ${ }^{22} 26-31$ This adds a different light to the study of Miklos and Moore, ${ }^{16}$ which found that $37 \%$ sought FGCS for aesthetic reasons only, 32\% for functional impairment, $31 \%$ for functional and aesthetic reasons. Many studies report size of the labia minora as the most common concern, and that most women seeking genital cosmetic surgery believe that their labia minora are too visible; ${ }^{2} 8111628$ however, the psychological and emotional drivers for wanting surgery are as yet, less well researched.

Adolescents see GPs for genital anatomy concerns also and the Australian Medicare statistics so far indicate that FGCS incidence in the group aged 15-25 has matched the group aged $26-45,{ }^{4}$ which are similar to findings in the $\mathrm{UK}^{5}$ and USA. ${ }^{3}$ More than half the GPs surveyed also believed that it should not be performed on women $<18$ years, unless for genuine medical reasons, which complies with the recommendations from the joint Royal College of Obstetricians and Gynaecologists and British Society of Paediatric and Adolescent Gynaecology (BritsPAG) position statement. ${ }^{32}$ GPs conveyed the importance of appropriate referral to either a gynaecologist, cosmetic surgeon or mental health professional (table 7). This raises some significant issues for the GP, since the Medical Board of Australia issued the Cosmetic Surgery Guidelines in March 2016, ${ }^{31}$ which 
state that 'for major cosmetic procedures', which encompasses FGCS, 'patients under the age of 18 should be referred for mandatory psychological evaluation and have a 3 month cooling off period'. The psychological evaluation can now be conducted by a GP (who does not perform cosmetic procedures), or by a psychologist or psychiatrist. The guidelines do not directly address the BritsPAG call for consideration of delayed genital maturation which occurs around the age of 18 .

GPs in this survey desired more information regarding this surgical trend to support their patients with confidence. The RACGP resource guide was launched 1 week before the women's and children's health seminar and the survey revealed that only $6 \%$ of the total respondents knew about it and had accessed it. Although GPs have to date received little formal training or education on the topic, the survey findings suggest that $51 \%$ of GPs do make the effort to discuss the possible risks of surgery.

\section{Strengths and limitations}

Strengths include this being the largest study of GPs to date. Although the GP demographic is not representative of all Australian GPs which may indicate bias, it does however comprise mostly of female GPs with an interest in women's health, half of whom have experience in managing patients who have requested FGCS and this may in turn increase the validity of these findings. This GP demographic would by extension see more female patients who have genital anatomy concerns or are inquisitive regarding FGCS procedures than other $\mathrm{GPs}^{33}$ and as such, provides insight into knowledge gaps, concerns and recommendations of experienced GPs. It can provide a useful baseline of information from which further research in areas of GP knowledge of FGCS, genital anatomy, GP counselling skills along with the impact of teaching tools can be instigated. A limitation of the study is that the findings cannot be generalised to the rest of the GP population; however, the level of knowledge in other GPs might be even lower. The genital anatomy concerns and FGCS requests the GP sees may herald significant underlying mental health, sexual and domestic abuse issues, that have not yet been diagnosed and it is important that the GP be mindful of this when giving advice and consider appropriate referral.

Limitations of the study are that the group who responded may have self-selected due to the seminar content and differentiation of the survey respondents was based on timing of survey response rather than seminar attendance. The composite of GP experiences and management derived from the answers covered a wide range of GP experiences and asked for the GPs' view of why patients requested FGCS and how prepared the GPs felt to handle these questions. The GP interpretations, however, could be a mix of what the patient has told them and what is derived from their own clinical judgement. While some of the questions are open to subjective interpretation, the tables do however provide a broad baseline of responses that outlines GP experience and behaviour. Such a foundation can be useful in developing GP and patient resources along with areas for further study. Other limitations pertain to the use of terms such as 'counselling' and 'sexual dysfunction' which were not specified in detail in order to simplify the survey and increase participation. Although the two open-ended questions identified a diverse range of themes and effort was made to present the breadth of themes, the responses lack the richness of qualitative interviews. The identified themes should be further explored through indepth interviews. The sociocultural influences were not differentiated in relation to patient age group and as such, we could not distinguish differences between adolescents who might be responding to peer comments, the pressures of the fashion industry and exposure to pornography, compared with the older woman following childbirth or on entering a new relationship after divorce who might seek FGCS wanting 'the new look' and the 'new me'. ${ }^{18}$ The terms 'low', 'medium' or 'high' were used as a measure of levels of confidence rather than a numerical scale, thereby increasing the variability of the response according to personal interpretation.

The aim of any doctor-patient interaction should be to provide the patient with the best and most appropriate care for the presenting symptom and ultimately to do no harm, whether that be short term or long term. ${ }^{33}$ The surge in requests for FGCS has implications for the clinician and the RACGP guide can provide GPs with information sufficient to enable them to assist women to make better informed choices. ${ }^{19}$ There is need to explore reasons influencing the rise in surgery requests for adolescents under the age of 18 and to conduct objective research of long-term and short-term risks of FGCS that evaluate sexual satisfaction and aesthetic appearance satisfaction. Further research that explores the degree and range of psychological disturbances that motivate the FGCS requests would be welcomed as would a follow-up study to evaluate the impact of the RACGP guide in addressing GP needs.

\section{CONCLUSION}

GPs see females of all ages regarding genital anatomy concerns and for FGCS requests. Most of the GPs who had managed patient requests for FGCS felt underprepared to provide advice and requested professional education. Females of all ages, some with complex psychosocial and mental health issues, requested FGCS information of the GPs which suggests that the GP is seen as an important information source, who in turn can play a pivotal role in patient education and care in this emerging area.

Author affiliations

${ }^{1}$ Department of General Practice, University of Melbourne, Carlton, Victoria, Australia 
${ }^{2}$ Royal Australian College of General Practitioners, Expert Committee Quality Care, Melbourne, Victoria, Australia

${ }^{3}$ Sydney Medical School Northern, The University of Sydney, Sydney, New South Wales, Australia

${ }^{4}$ Academic Department of Psychiatry, Kolling Institute, Northern Sydney Local Health District, St Leonards, New South Wales, Australia

${ }^{5}$ Faculty of Medicine, Nursing and Health Sciences, Monash University, Clayton, Victoria, Australia

${ }^{6}$ Melbourne Sexual Health Centre, Carlton, Victoria, Australia

Twitter Follow Magdalena Simonis at @Cyclades12

Acknowledgements Acknowledgment should go to Susan Bewley, Lih-Mei Liao, Sarah Creighton, Naomi Crouch for their preliminary research, which inspired MS to examine the GP role more closely. The authors also thank Healthed for facilitating the development and execution of the survey and Healthed's delegates who participated in the survey.

Contributors This paper was written by MS, supervised by JJO and RM. Together, they designed the survey, analysed data and discussed the findings. MS was solely responsible for the literature review and RM arranged the survey distribution by email to the database of consenting GPs.

Funding HealthEd distributed the survey without charge and provided funding for the publication costs. JJO receives funding from the National Health and Medical Research Council as an Early Career Fellow (APP1104781).

Competing interests MS is on the RACGP Expert Committee of Quality Care and in 2015, she authored the RACGP guide on FGCS titled, 'Female genital cosmetic surgery: a resource for general practitioners and other health professionals'; she has also participated in the development of FGCS guidelines for GPS.

Patient consent Obtained.

Ethics approval Alfred Health Human Ethics Committee (Project 348/15).

Provenance and peer review Not commissioned; externally peer reviewed.

Data sharing statement Extra data can be accessed via the Dryad data repository at http://datadryad.org/ with the doi:10.5061/dryad.b16n8.

Open Access This is an Open Access article distributed in accordance with the Creative Commons Attribution Non Commercial (CC BY-NC 4.0) license, which permits others to distribute, remix, adapt, build upon this work noncommercially, and license their derivative works on different terms, provided the original work is properly cited and the use is non-commercial. See: http:// creativecommons.org/licenses/by-nc/4.0/

\section{REFERENCES}

1. Bramwell R, Morland C. Genital appearance satisfaction in women: the development of a questionnaire and exploration of correlates. $J$ Reprod Infant Psychol 2009;27:15-27.

2. Pardo J, Ricci P, Sola V. Comment on Pauls: 'Nip, tuck and rejuvenate: the latest frontier for the gynecologic surgeon'. Int Urogynecol J Pelvic Floor Dysfunct 2008;19:889-90. author reply 91 .

3. The American Society of Aesthetic Plastic Surgery. Cosmetic surgery national data bank statistics. http://www.surgery.org/sites/ default/files/Stats2013_3.pdf

4. Australian Government Department of Human Services. Medicare Item Reports. http://medicarestatistics.humanservices.gov.au/ statistics/mbs_item.jsp

5. British Association of Aesthetic Plastic Surgeons. Aesthetic genital surgery: female genital aesthetic surgery (aesthetic genital surgery, designer vaginas). London. http://www.baaps.org.uk/procedures/ aesthetic-genital-surgery

6. Australian Government Department of Health. MBS reviews: vulvoplasty report. http://www.health.gov.au/internet/main/publishing. nsf/Content/vulvoplasty
7. Braun V. Female genital cosmetic surgery: a critical review of current knowledge and contemporary debates. J Women's Health 2010;19:1393-407.

8. Deans R, Liao LM, Crouch NS, et al. Why are women referred for female genital cosmetic surgery? Med J Aust 2011;195:99.

9. Michala L, Liao L-M, Creighton S. Female genital cosmetic surgery: how can clinicians act in women's best interests? Obstet Gynaecol 2012;14:203-6.

10. Liao LM, Creighton SM. Requests for cosmetic genitoplasty: how should healthcare providers respond? BMJ 2007;334:1090-2.

11. Liao LM, Taghinejadi N, Creighton SM. An analysis of the content and clinical implications of online advertisements for female genital cosmetic surgery. BMJ Open 2012;2:pii: e001908

12. Alter GJ. Labia minora reconstruction using clitoral hood flaps, wedge excisions, and YV advancement flaps. Plast Reconstr Surg 2011;127:2356-63.

13. Pardo J, Sola V, Ricci $P$, et al. Laser labioplasty of labia minora. Int J Gynaecol Obstet 2006;93:38-43.

14. Sharp G, Tiggemann M, Mattiske J. Factors that influence the decision to undergo labiaplasty: media, relationships, and psychological well-being. Aesthet Surg J 2016;36:469-78.

15. Rouzier R, Louis-Sylvestre C, Paniel BJ, et al. Hypertrophy of labia minora: experience with 163 reductions. Am J Obstet Gynecol 2000;182(Pt 1):35-40.

16. Miklos JR, Moore RD. Labiaplasty of the labia minora: patients indications for pursuing surgery. J Sex Med 2008:5:1492-5.

17. Liao LM, Creighton SM. Female genital cosmetic surgery: a new dilemma for GPs. Br J Gen Pract 2011;61:7-8.

18. Harding $\mathrm{T}$, Hayes J, Simonis $\mathrm{M}$, et al. Female genital cosmetic surgery: investigating the role of the general practitioner. Aust Fam Physician 2015;44:822-5.

19. Female genital cosmetic surgery-a resource for general practitioners and other health professionals. Melbourne: The Royal Australian College of General Practitioners. http://www.racgp.org.au/ your-practice/guidelines/female-genital-cosmetic-surgery/

20. Sandelowski M. Whatever happened to qualitative description? Res Nurs Health. 2000;23:334-40.

21. Neergaard MA, Olesen F, Andersen RS, et al. Qualitative description-the poor cousin of health research? BMC Med Res Methodol 2009:9:52.

22. Nappi RE, Liekens G, Brandenburg U. Attitudes, perceptions and knowledge about the vagina: the International Vagina Dialogue Survey. Contraception 2006;73:493-500.

23. Howarth C, Temple-Smith M, Simonis M, et al. What are young women's views on 'normal' and 'desirable' vulval anatomy? https://www.eiseverywhere.com/file_uploads/ ed79ecbebf9c6e149a40a8b9f0263226 PosterNumber 75.pdf

24. Andrikopoulou M, Michala L, Creighton SM, et al. The normal vulva in medical textbooks. J Obstet Gynaecol 2013;33:648-50.

25. Britt $\mathrm{H}$, Miller $\mathrm{G}$, Charles J, et al. A decade of Australian general practice activity 2002-03 to 2011-12. General Practice Series no. 32. Sydney: Sydney University Press, 2012. http://ses.library.usyd. edu.au/handle/2123/9365

26. Zwier S. 'What Motivates Her': motivations for considering labial reduction surgery as recounted on women's online communities and surgeons' websites. Sex Med 2014;2:16-23.

27. Lloyd J, Crouch NS, Minto CL, et al. Female genital appearance: 'normality' unfolds. BJOG 2005;112:643-6.

28. Michala L, Koliantzaki S, Antsaklis A. Protruding labia minora: abnormal or just uncool? J Psychosom Obstet Gynaecol 2011:32:154-6.

29. Liao LM, Michala L, Creighton SM. Labial surgery for well women: a review of the literature. BJOG 2010;117:20-5.

30. Berman L, Berman J, Miles M, et al. Genital self-image as a component of sexual health: relationship between genital self-image, female sexual function, and quality of life measures. J Sex Marital Ther 2003;29(Suppl 1):11-21.

31. Mowat H, McDonald K, Dobson AS, et al. The contribution of online content to the promotion and normalisation of female genital cosmetic surgery: a systematic review of the literature. BMC Womens Health 2015;15:110.

32. Royal College of Obstetricians and Gynaecologists joint British Society of Paediatric and Adolescent Gynaecologists. Joint RCOG/ BritSPAG release: issues surrounding women and girls undergoing female genital cosmetic surgery explored. (October 2013). https:// www.rcog.org.uk/en/news/joint-rcogbritspag-release-issuessurrounding-women-and-girls-undergoing-female-genitalcosmetic-surgery-explored/

33. Harris MF, Harris E. Facing the challenges: general practice in 2020 . Med J Aust 2006;185:122-4. 